\title{
Stage-related Proliferative Activity Determines c-myb Functional Requirements during Normal Human Hematopoiesis
}

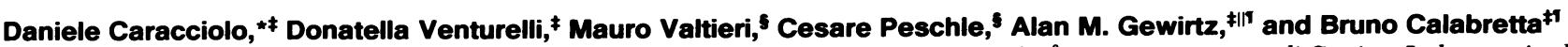 \\ ${ }^{*}$ Istituto di Medicina ed Oncologia Sperimentale, Sezione di Ematologia, Torino, Italy; ${ }^{\S}$ Istituto Superiore di Sanita, Laboratorio di \\ Ematologia, Rome, Italy; and "Thrombosis Research Center, ${ }^{\ddagger}$ Departments of Medicine and Pathology, and ${ }^{\top}$ Fels Research Institute, \\ Temple University School of Medicine, Philadelphia, Pennsylvania 19140
}

\begin{abstract}
To determine if MYB protein is preferentially required during specific stages of normal human hematopoiesis we incubated normal marrow mononuclear cells (MNC) with c-myb antisense oligodeoxynucleotides. Treated cells were cultured in semisolid medium under conditions designed to favor the growth of specific progenitor cell types. Compared with untreated controls, granulocyte-macrophage (GM) CFU-derived colonies decreased $77 \%$ when driven by recombinant human (rH) IL-3, and 85\% when stimulated by rH GM colony-stimulating factor (CSF); erythroid burst-forming unit (BFU-E)and CFU-E-derived colonies decreased 48 and $78 \%$, respectively. In contrast, numbers of G-CSF-stimulated granulocyte colonies derived from antisense treated $\mathrm{MNC}$ were unchanged from controls, though the numbers of cells composing these colonies decreased $\sim 90 \%$. Similar results were obtained when $\mathrm{MY10}^{+}$cells were exposed to c-myb antisense oligomers. When compared with untreated controls, numbers of CFUGM and BFU-E colonies derived from MY10 ${ }^{+}$cells were unchanged, but the numbers of cells composing these colonies were reduced $\sim 75$ and $>90 \%$, respectively, in comparison with controls. c-myc sense and antisense oligomers were without significant effect in these assays. Using the reverse transcription-polymerase chain reaction, c-myb mRNA was detected in developing hematopoietic cells on days 0-8. At day 14 c-myb expression was no longer detectable using this technique. These results suggest that $c-m y b$ is required for proliferation of intermediate-late myeloid and erythroid progenitors, but is less important for lineage commitment and early progenitor cell amplification. (J. Clin. Invest. 1990. 85:55-61.) antisense $\bullet c-m y b \cdot$ hematopoiesis
\end{abstract}

\section{Introduction}

Normal circulating myeloid and erythroid cells are derived from a small complement of bone marrow progenitors that give rise to these morphologically recognizable elements after a myriad of cell proliferation and maturation events $(1,2)$. The molecular processes that regulate these events, especially in humans, remain largely unknown because of difficulties in

Address correspondence to Dr. Gewirtz or Dr. Calabretta, Departments of Medicine and Pathology, Temple University School of Medicine, 3400 North Broad St., Philadelphia, PA 19140.

Received for publication 27 March 1989 and in revised form 23 June 1989.

J. Clin. Invest.

(c) The American Society for Clinical Investigation, Inc.

0021-9738/90/01/0055/07 \$2.00

Volume 85, January 1990, 55-61 isolating sufficient cellular material with which to conduct such investigations. Based on studies demonstrating that the generation of hematopoietic colonies closely mimics in vivo hematopoiesis (3-5); that a variety of recombinant hematopoietic growth factors can be used for the growth of specific progenitor cell types $(6,7)$; and that antisense oligodeoxynucleotides can block the activity of specific genes in hematopoietic cells $(8-10)$, we have developed a strategy that allows direct assessment of the role of specific genes in regulating hematopoiesis. With this approach we recently showed that exposure of partially purified human hematopoietic progenitor cells to a synthetic oligodeoxynucleotide complementary to c-myb mRNA inhibits human hematopoietic colony formation in vitro (11). Although those studies provided direct evidence that the c-myb gene product plays an important role in regulating hematopoiesis, the stage of hematopoietic development during which c-myb gene function is most important remained unknown. In particular, it remained unclear whether c-myb function was most relevant for the proliferation of progenitor cells or whether it was needed at an earlier (lineage commitment) or later (precursor differentiation) stage of hematopoietic development. To address these questions, we analyzed the growth of late and early progenitors in vitro after exposure to a $c-m y b$ antisense oligomer. Our findings suggest that c-myb gene function is preferentially required for the proliferation of intermediate-late hematopoietic progenitors; is less critical for the proliferation of early progenitors; and may not be required for lineage commitment.

\section{Methods}

Cells. Human bone marrow cells were obtained from normal healthy volunteers after informed consent. Light density mononuclear cells (MNC)' were obtained by Ficoll-Hypaque density gradient centrifugation and enriched for hematopoietic progenitors by first removing adherent and phagocytic elements and then $T$ lymphocytes as previously described (12). MNC depleted of adherent/phagocytic and T cells $\left(\mathrm{A}^{-} \mathrm{T}^{-} \mathrm{MNC}\right)$ were then plated in semisolid medium or further enriched for immature progenitors by immunorosetting with antiHPCA-1 MAb (Becton Dickinson, Mountain View, CA), which recognizes the MY10 or CD34 antigen (13). Briefly, packed sheep red blood cells (SRBC) were incubated with an equal volume of $0.1 \% \mathrm{CrCl}_{3}$ and $\mathrm{F}(\mathrm{ab})_{2}$ goat anti-mouse affinity-purified $\mathrm{F}(\mathrm{ab})_{2}(1 \mathrm{mg} / \mathrm{ml}$; Cappel Labo-

1. Abbreviations used in this paper: $\mathrm{A}^{-} \mathrm{T}^{-} \mathrm{MNC}, \mathrm{MNC}$ depleted of adherent/phagocytic and T cells; BFU-E, burst-forming unit-erythrocyte; CFU-E, CFU erythrocyte; CFU-G, CFU granulocyte; CFU-GM, CFU granulocyte/macrophage; FBS, fetal bovine serum; G-CSF, granulocyte colony-stimulating factor; GM-CSF, granulocyte/macrophage colony-stimulating factor; IMDM, Iscove's modified Dulbecco's medium; MNC, mononuclear cells; RT-PCR, reverse transcriptasepolymerase chain reaction; SRBC, sheep red blood cells. 
ratories, Cochranville, $\mathrm{PA}$ ) for $10 \mathrm{~min}$ at room temperature. SRBC were then extensively washed in normal saline and resuspended at a concentration of $2 \%$ in normal saline $(200 \mu l$ of packed SRBC in a final volume of $10 \mathrm{ml})$. Marrow cells were incubated for $60 \mathrm{~min}$ at $4^{\circ} \mathrm{C}(6$ $\left.\times 10^{6} \mathrm{cells} / \mathrm{ml}\right)$ in the presence of 1:50 anti-HPCA-1 MAb. After extensive washing, antibody-treated SRBC $\left(0.4 \mathrm{ml} / 10^{6}\right.$ cells $)$ were added to cells, pelleted, and incubated for $1 \mathrm{~h}$ at $4^{\circ} \mathrm{C}$. Rosetted cells were then separated on a Ficoll gradient and SRBC were subsequently eliminated with a lysing reagent (Ortho Pharmaceutical, Raritan, NJ).

Colony assays. $2.5 \times 10^{4} \mathrm{~A}^{-} \mathrm{T}^{-} \mathrm{MNC}$ or $4 \times 10^{3} \mathrm{MY}^{-} 0^{+} \mathrm{MNC}$ were plated in Iscove's modified Dulbecco's medium (IMDM) supplemented with $20 \%$ fetal bovine serum (FBS) and 0.3\% agar (Difco Laboratories Inc., Detroit, MI) or in IMDM, $30 \%$ FBS, $10^{-4} \mathrm{M}, \beta$ mercaptoethanol (Sigma Chemical Co., St. Louis, MO), and 0.9\% methylcellulose (Dow Chemical Co., Indianapolis, IN) in 35-mm petri dishes (Corning Glass Works, Corning, NY) at $1 \mathrm{ml} /$ dish. For myeloid colony stimulation, granulocyte/macrophage colony-stimulating factor (GM-CSF; $5 \mathrm{ng} / \mathrm{ml})$, IL-3 $(20 \mathrm{U} / \mathrm{ml}$ ), or (granulocyte colony-stimulating factor (G-CSF; $10 \%$ of transfected Chinese hamster ovary cell supernatant) were used. CFU erythroid (CFU-E) colonies were obtained in the presence recombinant human erythropoietin alone (3 $\mathrm{U} / \mathrm{ml}$; Amgen Biologicals, Thousand Oaks, CA). Burst-forming unitserythroid (BFU-E) colonies were obtained in the presence of a combination of IL-3 $(10 \mathrm{U} / \mathrm{ml}), \mathrm{GM}-\mathrm{CSF}(5 \mathrm{ng} / \mathrm{ml})$, and erythropoietin (3 $\mathrm{U} / \mathrm{ml})$. Colonies were scored after 14-16 d of culture in a humidified $5 \% \mathrm{CO}_{2}$ incubator. CFU-E and G-CSF-stimulated granulocytic colonies were scored at 7-9 d of culture. To determine colony size, 30 consecutive individual colonies from each plate were plucked from methylcellulose, dispersed in tissue culture medium, and then counted in a hemocytometer. Cells in smaller colonies were counted directly in the plates.

Oligodeoxynucleotides. Unmodified, 18-base oligodeoxynucleotides were made on a DNA synthesizer (model 380B; Applied Biosystems Inc., Foster City, CA) by means of $\beta$-cyanoethyl-phosphorymidite chemistry. Oligodeoxynucleotides were purified by ethanol precipitation and multiple washes in $70 \%$ ethanol. They were subsequently lyophilized to dryness and redissolved in culture medium at a concentration of $1 \mathrm{mg} / \mathrm{ml}$. The sequence of the c-myb antisense oligomer is $5^{\prime}$-GTGCCGGGGTCTTCGGGC-3' and is complementary to $18 \mathrm{nu}$ cleotides starting from the second codon of c-myb mRNA (14); the $c-m y b$ sense oligomer has the sequence 5'-GCCCGAAGACCCCGGCAC-3'. The sequence of the c-myc antisense oligomer is $5^{\prime}-$ GAAGCTAACGTTGAGGGG-3' and is complementary to 18 nucleotides starting from the second codon of c-myc mRNA (15). The c-myc sense oligomer has the sequence 5'-CCCCTCAACGTTAGCTTC-3'.

Oligomer treatment of cells. $2.5 \times 10^{4} \mathrm{~A}^{-} \mathrm{T}^{-} \mathrm{MNC}$ or $4 \times 10^{3}$ $\mathrm{MY} 10^{+} \mathrm{MNC}$ from each sample were incubated in $0.2 \mathrm{ml}$ of IMDM $20 \%$ FBS in polypropylene tubes (Falcon Plastics, Cockeysville, MD) in the presence of optimal concentrations of the relevant hematopoietic growth factor. Some cultures were also supplemented with 100 $\mu \mathrm{g} / \mathrm{ml}$ of either sense or antisense oligomers for $18 \mathrm{~h}$ at a final concentration of $17.5 \mu \mathrm{M}$. Cells were not washed before plating. Control cultures were left untreated.

Detection of c-myb MRNA in bone marrow cells by reverse transcriptase-polymerase chain reaction (RT-PCR) analysis. Expression of c- $m y b$ mRNA in $\mathrm{A}^{-} \mathrm{T}^{-} \mathrm{MNC}$ and $\mathrm{MY} 10^{+} \mathrm{MNC}$ was analyzed as follows: cells seeded at $4 \times 10^{4}$ were collected at the end of the required time of culture and total RNA was extracted in the presence of $20 \mu \mathrm{g}$ of Escherichia coli ribosomal RNA as described (16). RNA was then reverse-transcribed using $500 \mathrm{U}$ of Moloney murine leukemia virus reverse transcriptase and $0.2 \mu \mathrm{g}$ of oligo(dT) as primer for $1 \mathrm{~h}$ at $37^{\circ} \mathrm{C}$. The resulting cDNA fragments were amplified with $7.5 \mathrm{U}$ of Thermus aquaticus (Taq) polymerase in the presence of c-myb mRNA sequence-specific synthetic primers; the 5 ' oligonucleotide corresponds to the c-myb mRNA sequence from nucleotides $2,258-2,279$ and the $3^{\prime}$ oligonucleotide corresponds to nucleotides $2,466-2,487$. Therefore, a 230 -bp fragment corresponding to a portion of the $3^{\prime}$ untranslated region of c-myb (14) was generated during 60 cycles of polymerase chain reaction (17). $10 \mu \mathrm{l}$ of the $50-\mu \mathrm{l}$ polymerase chain reaction was separated in a $4 \%$ Nusieve agarose gel and transferred to a nitrocellulose filter. The resulting blot was hybridized with a synthetic 50-base c-myb oligomer complementary to the amplified c-myb cDNA from nucleotides 2,351-2,400 (14). The synthetic c-myb oligomer was endlabeled with $\left[{ }^{32} \mathrm{P}\right] \gamma$-ATP and polynucleotide kinase as described (18).

Detection of myb protein. $5 \times 10^{4} \mathrm{MY}^{+} 0^{+} \mathrm{MNC}$, separated as described above, were plated in 96-well plates (Costar, Cambridge, MA) in $200 \mu \mathrm{l} / \mathrm{IMDM}, 20 \% \mathrm{FBS}$ per well in the presence of GM-CSF $(5 \mathrm{ng} / \mathrm{ml})$ plus IL-3 $(20 \mathrm{U} / \mathrm{ml})$. At days 0 and 21 of culture in a humidified incubator at $37^{\circ} \mathrm{C}$ cells were placed on polylysine-treated slides, cytocentrifuged at $400 \mathrm{rpm}$ for $5 \mathrm{~min}$ (Shandon II), and fixed with methanol/acetone (1:9) for $15 \mathrm{~min}$ at room temperature. Expression of myb antigen was assessed by indirect immunofluorescence with a sheep anti-human myb serum (Cambridge Research Biochemicals, Valley Stream, NY) at a 1:40 dilution $(19,20)$.

\section{Results}

Effect of sense and antisense myb and myc oligomers on human bone marrow $\left(A^{-} T^{-} M N C\right)$. $\mathrm{A}^{-} \mathrm{T}^{-} \mathrm{MNC}$ were exposed to oligomer preparations for $18 \mathrm{~h}$ and then cloned in cultures optimized for the growth of specific progenitor cell subsets (see methods). Data relative to erythroid progenitor cell growth are shown in Fig. 1. Bars express percent of growth of antisensevs. sense-treated cells (assumed as 100\%) and are mean \pm SD of three different experiments. Mean colony yield was $54 \pm 2(2.5$ $\times 10^{4}$ cells plated) for BFU-E and $298 \pm 20$ for CFU-E in three different experiments. Sense oligomers gave 2-20\% inhibition compared with untreated controls. Treatment with the c-myb antisense oligomer resulted in a $48 \%$ decrement in the number of BFU-E colonies, whereas the decrease of CFU-E colonies was $78 \%$, a value consistent with our previous findings (11). Colony size was also analyzed (Table I). In the case of BFU-E, median colony size was 12,000 for untreated controls. Sense oligomers gave only a small reduction in the number of cells per colony $(10,000=16.6 \%$ inhibition $)$, whereas antisense oligomers effected a drastic reduction in colony size $(1,500$ cells per colony $=87.5 \%$ inhibition). When erythroid colonies formed in the presence of a c-myc antisense oligomer, no decrement in either colony size or number was noted as compared with control colonies. An analysis of myeloid colony formation in the presence of $c-m y b$ and c-myc oligomers is shown in Fig. 2. Data relative to CFU-granulocyte/macrophage (CFUGM) growth in the presence of IL-3 or GM-CSF, and G-CSFstimulated CFU-granulocyte (CFU-G) growth are presented. Mean colony yield (per $2.5 \times 10^{4}$ cells plated) was $83 \pm 6$ and

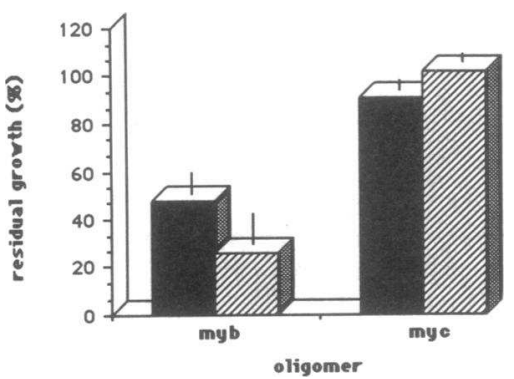

Figure 1. Effect of antisense vs. sense c-myb and c-myc oligomers on in vitro colony formation of human erythroid progenitors. Bars express percent of colony number of antisense- vs. sense-treated $\mathrm{A}^{-} \mathbf{T}^{-} \mathrm{MNC}$. Values are mean \pm SD of three and four different experiments for BFU-E ( $\square$ ) and CFU-E ( $\square$ ), respectively, from duplicate plates. CFU-E were scored after $7 \mathrm{~d}$ of culture. BFU-E were scored after $16 \mathrm{~d}$ of culture. 
Table I. Effect of Sense and Antisense Oligodeoxynucleotides on the Size of Colonies Obtained from $A^{-} T^{-} M N C$

\begin{tabular}{|c|c|c|c|}
\hline & \multicolumn{3}{|c|}{ Erythroid progenitors } \\
\hline & \multicolumn{2}{|c|}{ BFU-E } & CFU-E \\
\hline Control & \multicolumn{2}{|c|}{$12,000(10,500-14,000)$} & $36(6-40)$ \\
\hline$c-m y b$ sense & \multicolumn{2}{|c|}{$10,000(9,000-10,500)$} & $38(6-40)$ \\
\hline$c-m y b$ antisense & \multicolumn{2}{|c|}{$1,500(1,000-2,000)$} & $36(6-40)$ \\
\hline \multirow[t]{3}{*}{$c-m y c$ antisense } & $12,500(11$ & $1,000-14,000)$ & $37(6-40)$ \\
\hline & \multicolumn{3}{|c|}{ Myeloid progenitors } \\
\hline & CFU-GM (GM-CSF) & CFU-GM (IL-3) & CFU-G (G-CSF) \\
\hline \multirow{4}{*}{$\begin{array}{l}\text { Control } \\
c-m y b \text { sense } \\
c-m y b \text { antisense } \\
\text { c-myc antisense }\end{array}$} & $650(80-800)$ & $500(80-600)$ & $850(100-1,000)$ \\
\hline & $500(50-600)$ & $350(50-400)$ & $650(100-800)$ \\
\hline & $55(40-80)$ & $45(40-60)$ & $60(40-70)$ \\
\hline & $700(80-800)$ & $550(80-600)$ & $800(100-1,000)$ \\
\hline
\end{tabular}

Partially purified bone marrow cells $\left(\mathrm{A}^{-} \mathrm{T}^{-} \mathrm{MNC}\right)$ were cultured in semisolid medium under optimal conditions for the different subsets tested as described in Methods. After appropriate incubation time (14 d for BFU-E and CFU-GM, and 7-9 d for CFU-G and CFU-E, respectively) the colony size was evaluated. From each culture plate 30 consecutive individual colonies were examined for their size. For smaller colonies a cell count was made directly on the culture plate; bigger colonies were picked up with a drawn Pasteur pipette and dispersed in culture medium, and cells were counted in a hemocytometer. Numbers express the median value observed. The variation range is given in parentheses.

$163 \pm 9$ in GM-CSF- and IL-3-stimulated cultures, respectively. Treatment with sense oligomers resulted in a 6-20\% inhibition compared with growth in untreated control cultures. Regardless of the hemopoietin used, colony growth was inhibited in the presence of c-myb antisense oligomers (77\% inhibition of colonies formed in presence of IL-3 and 85\% inhibition of colonies formed in presence of GM-CSF). Most of the residual colonies were macrophage and eosinophilic in type. CFU-GM colony growth was unaffected when progenitor cells were exposed to c-myc antisense oligomers (94-112\% growth vs. controls).

Day 7 granulocyte progenitors (CFU-G) are developmentally more mature than day 14 CFU-GM and give rise to single lineage colonies in response to G-CSF after $7 \mathrm{~d}$ of culture. In

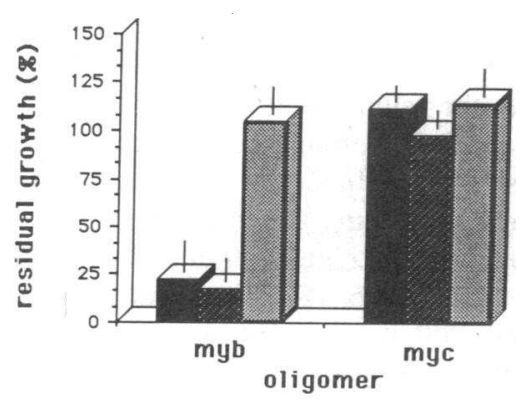

Figure 2. Effect of antisense vs. sense c-myb and $c-m y c$ oligomers on in vitro colony formation of human myeloid progenitors. Bars express percent of colony number of antisensevs. sense-treated $\mathbf{A}^{-} \mathbf{T}^{-} \mathbf{M N C}$. Values are mean $\pm S D$ of four different experiments from duplicate plates. Colonies were scored after $14 \mathrm{~d}$ of culture (7-9 $\mathrm{d}$ for G-CSF-stimulated cultures). $n$, CFU-GM (IL-3); ; , CFU-GM (GMCSF); घ, CFU-G (G-CSF). our culture system, control CFU-G cultures contained $327 \pm 28$ colonies per $2.5 \times 10^{4}$ cells plated. Treatment with c-myb sense oligomer inhibited the number of colonies in $9-20 \%$ of controls, and no further decrease in colony number was observed when cells were exposed to c-myb antisense or c-myc sense or antisense oligomers (Fig. 2). However, analysis of CFU-G colony size (Table I and Fig. 3) revealed a $\sim 90 \%$ reduction in the numbers of cells/colony formed in the presence of c-myb antisense oligomer (median size, 60 cells/colony) as compared with control colonies (median size, 850 cells/colony) or those arising in the presence of the c-myb sense oligomer (median size, 650 cells/colony) or the c-myc antisense oligomer (median size, 800 cells/colony).
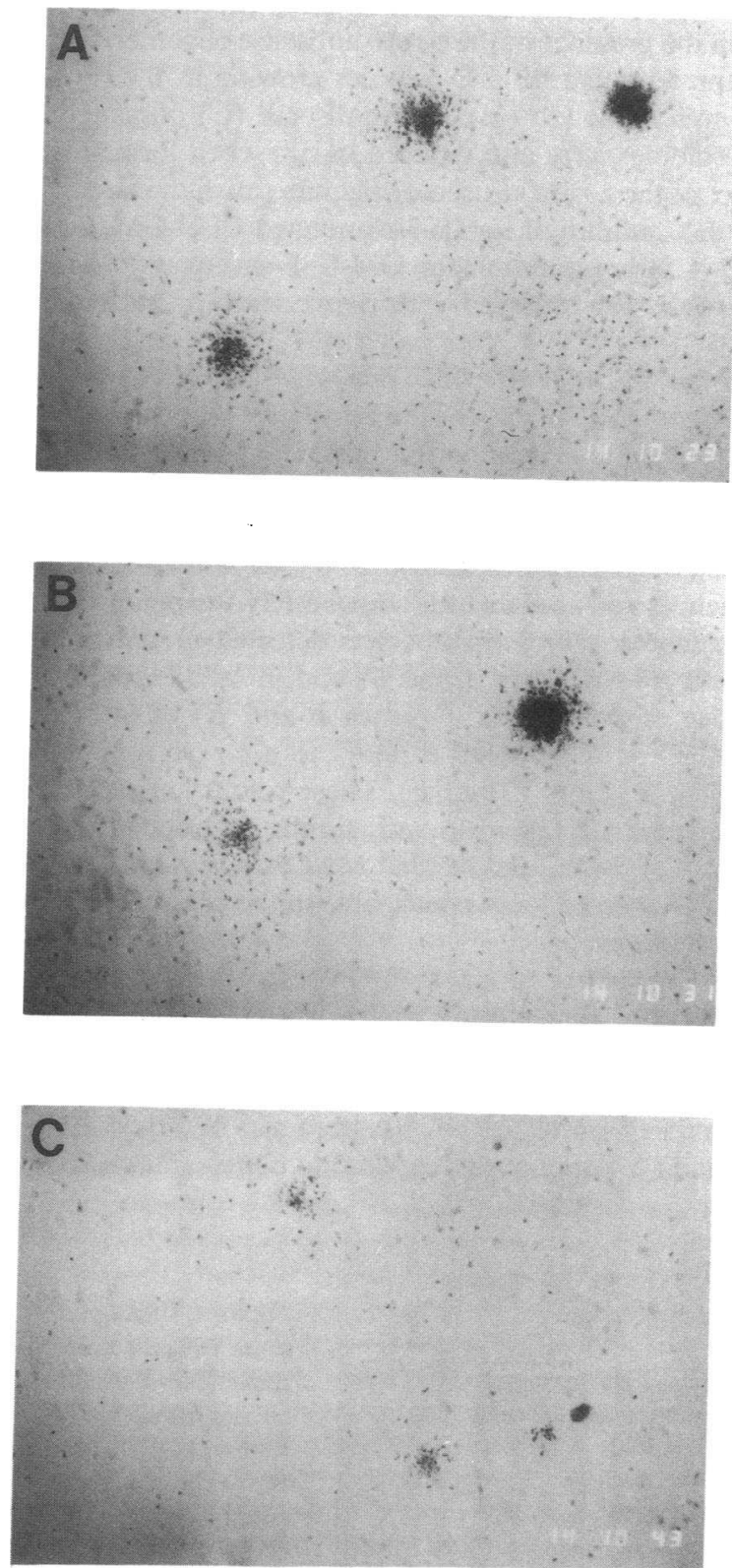

Figure 3. Effect of c-myb sense and antisense oligomers on neutrophilic granulocytic colony formation. CFU-G colonies grown in the presence of recombinant human G-CSF from $\mathrm{A}^{-} \mathrm{T}^{-} \mathrm{MNC}$ after $7 \mathrm{~d}$ of culture. $A$, control; $B$, colonies after treatment with a sense oligomer; $C$, colonies after treatment with an antisense oligomer. 
Effect of sense and antisense myb and myc oligomers on marrow $\mathrm{MY} 10^{+} \mathrm{MNC}$. To analyze the effect of antisense oligomers on the growth of a more homogeneous, less mature population of progenitors the same set of experiments were performed on marrow cells enriched for $\mathrm{MY}^{+} 0^{+} \mathrm{MNC}$. Because neither CFU-E nor CFU-G are contained within this cell population (21), only day 14 CFU-GM and BFU-E derived colonies were studied. Mean colony yield was $56 \pm 3$ for BFU-E and $63 \pm 6$ or $86 \pm 4$ for CFU-GM, stimulated with IL-3 or GM-CSF, respectively. Little inhibition in the numbers of colonies formed was observed in either the sense- or antisensetreated cultures (Fig. 4). However, colony size was consistently affected (Table II). Median colony size for BFU-E formed in presence of c-myb sense oligomer was 15,500 cells/colony. This value was reduced to 4,000 cells/colony (average inhibition $75 \%$ ) in the presence of the $c-m y b$ antisense oligomer. Fig. 5 shows representative BFU-E colonies growing in the presence of $c-m y b$ sense $(B)$ or c-myb antisense $(C)$ oligomers. CFU-GM colonies were also reduced in size when formed in the presence of the c-myb antisense oligomer (median value 55 vs. $700=93 \%$ inhibition for IL-3-stimulated CFU-GM, and 55 vs. $550=90 \%$ inhibition for GM-CSF-stimulated CFUGM). No effect was observed with c-myc sense or antisense oligomers.

Expression of c-myb mRNA in bone marrow cells exposed to $c-m y b$ oligomers. To address the possibility that the differential effect of the c-myb antisense oligodeoxynucleotides on the various progenitor subsets was due to differential cellular

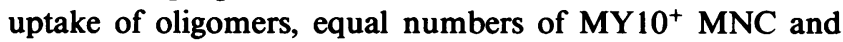
$\mathrm{A}^{-} \mathrm{T}^{-} \mathrm{MNC}\left(4 \times 10^{4}\right)$ were exposed to $c-m y b$ sense and antisense sequences and analyzed for $c-m y b$ mRNA expression by RT-PCR analysis. c- $m y b$ mRNA was detected in untreated marrow cells (Fig. 6, lanes $A$ and $D$ ) and in cells exposed to c- $m y b$ sense oligomer (Fig. 6, lanes $B$ and $E$ ) but not in $\mathrm{MY} 10^{+} \mathrm{MNC}$ or $\mathrm{A}^{-} \mathrm{T}^{-} \mathrm{MNC}$ exposed to a c-myb antisense oligomer (Fig. 6, lanes $C$ and $F$ ). These results suggest that c-myb oligomers are taken up with similar efficiency by the majority of $\mathrm{A}^{-} \mathrm{T}^{-} \mathrm{MNC}$ and $\mathrm{MY} 10^{+} \mathrm{MNC}$, since in both cases $c-m y b$ mRNA was no longer detectable in the presence of the antisense oligomer.

The disappearance of c-myb mRNA in antisense-treated cultures probably results from c-myb mRNA degradation after the formation of specific DNA-RNA duplexes that may provide a substrate for cellular RNase-H activity (22); a specific disappearance of c-myb mRNA has been also observed in peripheral blood $\mathrm{T}$ lymphocytes exposed to $\mathrm{c}-m y b$ antisense oli-

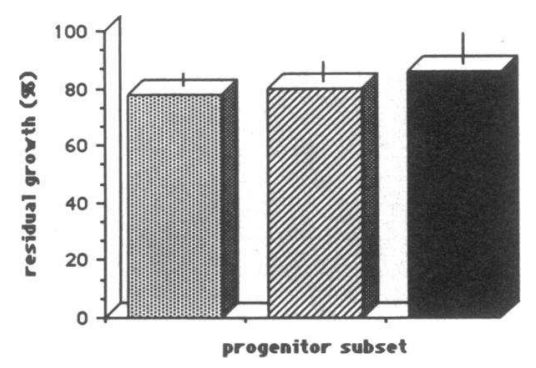

Figure 4. Effect of antisense vs. sense c-myb oligomers on in vitro colony formation of human $\mathrm{MY} 10^{+} \mathrm{MNC}$. Bars express percent of colony number of antisense- vs. sense-treated cultures. Values are mean \pm SD of three different experiments in

duplicate plates. $4 \times 10^{3}$ cells $/ \mathrm{ml}$ were plated. Colonies were scored after $16 \mathrm{~d}$ of culture. 1 , BFU-E; 1 , CFU-GM (IL-3); $₫$, CFU-GM (GM-CSF). godeoxynucleotides (20), and disappearance of c-abl transcripts has been observed in K562 cells exposed to c- $a b l$ antisense oligodeoxynucleotides (22a).

Detection of $c-m y b m R N A$ and $c-m y b$ protein during in vitro differentiation of $M Y 10^{+} M N C$. To follow the expression of c-myb mRNA during the differentiation of marrow MY $10^{+}$ MNC, these cells were cultured for different time periods in the presence of IL-3 and GM-CSF, and c- $m y b$ mRNA levels were measured by RT-PCR analysis using $1.6 \times 10^{5}$ or $1 \times 10^{5}$ cells. In each experiment 7-8 $\times 10^{7}$ marrow cells were used for purification with a final yield of $1-3 \times 10^{5} \mathrm{MY}^{+} 0^{+} \mathrm{MNC}$ enriched elements. Fig. 7 shows a Southern blot of the products of cDNA amplification using a $5^{\prime}$ and a $3^{\prime}$ c-myb sequence-specific primers hybridized to an end-labeled diagnostic probe 50 bases long corresponding to the amplified c-myb fragment from nucleotides 2,351-2,400 (14). A 230-bp c-myb amplified fragment is detected in $\mathrm{MY}^{+} 0^{+} \mathrm{MNC}$ at day 0 (Fig. 7, lane $A$ ) and after growth in culture in the presence of GMCSF and IL-3 for 4 and $8 \mathrm{~d}$ when c- $m y b$ mRNA levels were slightly increased (Fig. 7, lanes $B$ and $C$ ), but not after $14 \mathrm{~d}$ in culture (Fig. 7, lane $D$ ); in a second experiment c-myb mRNA was detected in $\mathrm{MY} 10^{+} \mathrm{MNC}$ at day 0 (Fig. 7, lane $E$ ) but was no longer detectable at day 14 (Fig. 7, lane $F$ ). This kinetics suggests that c-myb mRNA expression is maximal in actively cycling cultured $\mathrm{MY} 10^{+} \mathrm{MNC}$, whereas c-myb mRNA is undetectable when $\mathrm{MY} 10^{+} \mathrm{MNC}$ are well advanced in their process of differentiation (not shown). We also analyzed the expression of c-myb protein by immunofluorescence and in agreement with the observations of Kastan et al. (23) detected c-myb protein in marrow $\mathrm{MY} 0^{+}$on day 0 , but not after $21 \mathrm{~d}$ in culture in the presence of GM-CSF and IL-3 (not shown).

\section{Discussion}

Under homeostatic conditions hematopoiesis is maintained by a small subset of pluripotent stem cells and unipotent progenitor cells that reside in the $G_{0}$ phase of the cell cycle. When needed, these cells enter into the cell cycle, synthesize DNA, and divide to generate an amplified population of functionally mature elements. The cloning of the genes for several hematopoietic growth factors and the resulting production of the encoded recombinant proteins have led to major conceptual advances in understanding the regulation of normal hematopoiesis (6). However, the intermediary events that occur distal to the interaction between growth factors and their own receptors and the nuclear processes that specifically regulate proliferation and differentiation during hematopoietic development are still poorly understood (24). In theory, the activation of nuclear protooncogenes could provide a functional link between events occurring at the cellular membrane and the ensuing proliferative and maturative responses of the hematopoietic and other cellular systems (25). In fact, several studies have provided indirect evidence suggesting the importance of the c-myb nuclear protooncogene in regulating hematopoietic proliferation and differentiation (26-28). We recently took a direct approach and reported that a c-myb antisense oligomer inhibits in vitro growth of CFU-E, CFU-GM, and CFU-megakaryocyte colonies from normal bone marrow progenitors depleted of adherent cells and T lymphocytes (11). In the present study we analyzed different subsets of human hematopoietic progenitors to ascertain whether inhibition of colony forma- 
Table II. Effect of Sense and Antisense Oligodeoxynucleotides on the Size of Colonies Obtained from Marrow MY10 MNC

\begin{tabular}{lccc}
\hline & BFU-E & CFU-GM (IL-3) & CFU-GM (GM-CSF) \\
\hline Control & $17,500(16,000-20,000)$ & $1,000(100-1,200)$ & $700(100-800)$ \\
c-myb sense & $15,500(13,500-18,000)$ & $700(80-800)$ & $550(80-700)$ \\
c-my $b$ antisense & $4,000(3,500-5,000)$ & $55(40-80)$ & $55(40-60)$
\end{tabular}

MY10 MNC were cultured in semisolid medium under optimal culture conditions for the different subsets tested as described in Methods. After appropriate incubation time (16 d) the colony size was evaluated. For each culture plate the size of 30 consecutive individual colonies was examined as described in Table I. Numbers express the median value observed. The variation range is given in parentheses.

tion by a c-myb antisense oligomer is restricted to a specific level of maturation. Inhibition of the proliferation of erythroid progenitors was observed when the target cells analyzed were
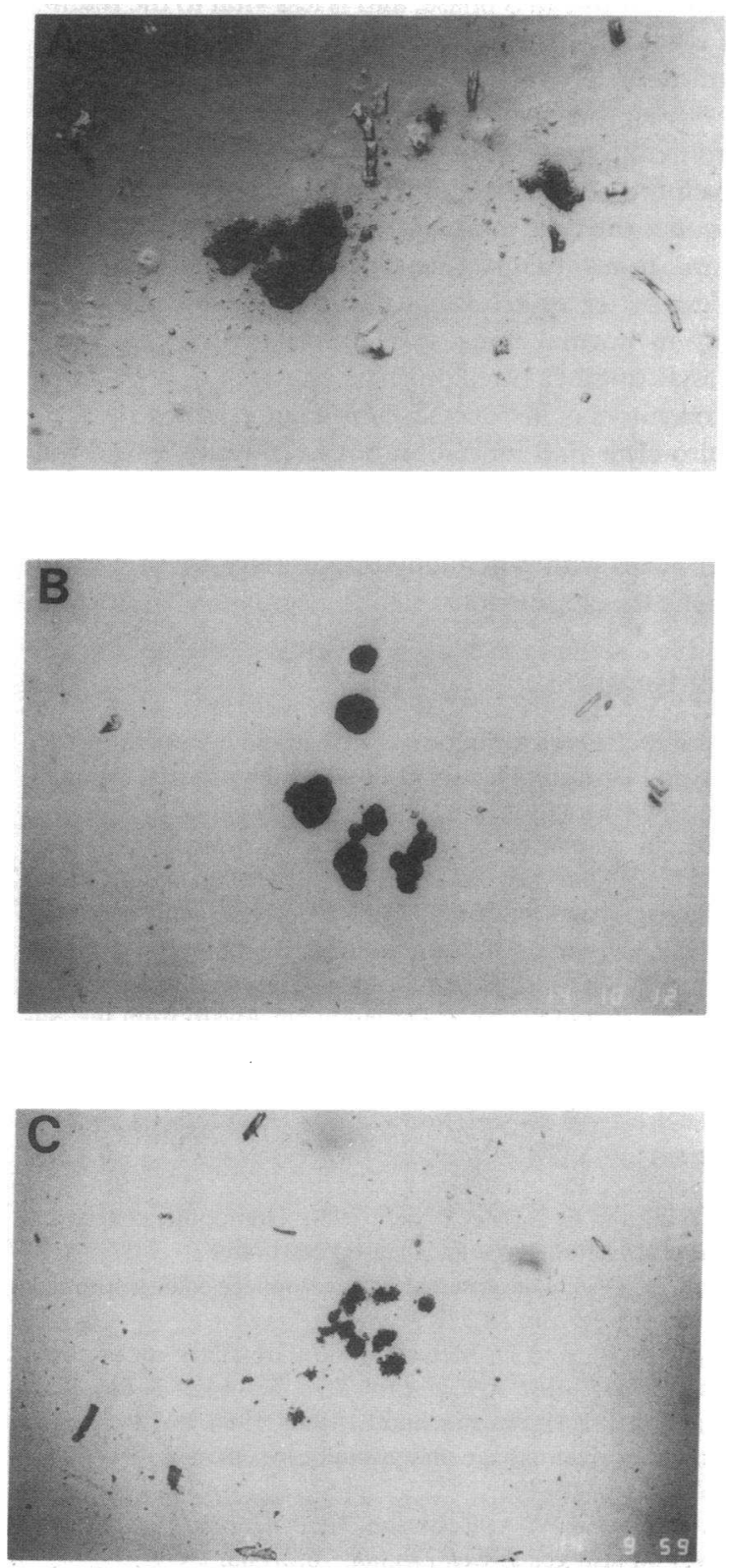

Figure 5. Erythroid bursts from MY $10^{+}$MNC. $A$, control; $B$, colonies after treatment with a c-myb sense oligomer, $C$, colonies after treatment with a c-myb antisense oligomer.
CFU-E and BFU-E derived from bone marrow cells depleted of adherent cells and $\mathrm{T}$ lymphocytes. Colony inhibition was most pronounced in CFU-E (22\% of that observed in c-myb sense-containing dishes) but was also observed in the growth of BFU-E colonies ( $52 \%$ of c- $m y b$ sense-treated dishes). No inhibition of colony number was observed with a subset of more primitive BFU-E derived from the population enriched in the more immature $\mathrm{MY} 10^{+}$progenitors (21), but colony size was much smaller (Table II, Fig. 5). Analogous results were obtained from BFU-E grown from peripheral blood (not shown), which is known to contain only the more immature progenitor subsets $(29,30)$.

Interestingly, the inhibitory effect of the c-myb antisense oligomer is most pronounced in the CFU-E compartment in which $60-80 \%$ of the cells are in $S$ phase and virtually all CFU-E are actively progressing through the cell cycle (31). In contrast, $<30 \%$ of the primitive BFU-E are in S phase and at least half of the cells in the BFU-E compartment are not cycling (31). Since the exposure of BFU-E progenitors to the $c-m y b$ antisense oligomer reduced the size of the BFU-E colonies without affecting the total colony number, it is likely that the antisense $c-m y b$ oligomer maximally inhibits colony formation once the primitive BFU-E enter into the pool of actively cycling progenitors.

A similar line of reasoning might explain the effects of the c-myb antisense oligomer on the CFU-GM and CFU-G progenitors. The most pronounced effect is on CFU-GM progenitors derived from partially purified marrow cells $(\sim 80 \%$ growth inhibition), while the effect on the more primitive

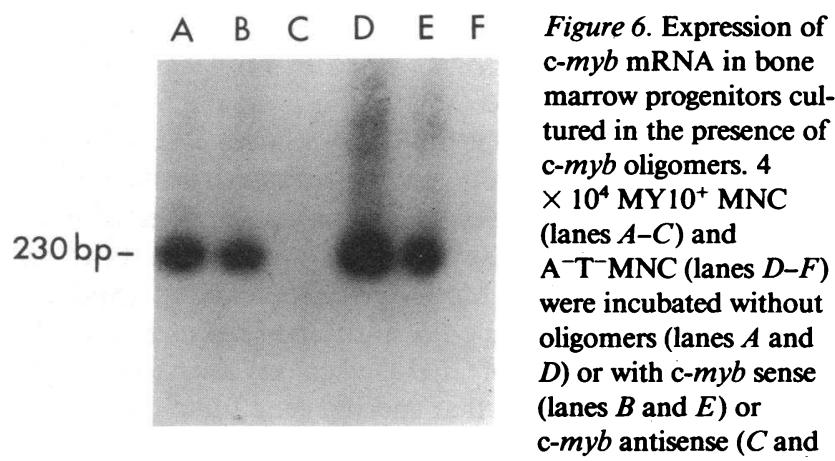

$F$ ) oligomers in the presence of IL-3 and GM-CSF. Cells were exposed to oligomers (final concentration $14 \mathrm{M}$ ) for $48 \mathrm{~h}$, collected, and total RNA extracted as described (16). c-myb mRNA was amplified by the RT-PCR technique (17) and detected by hybridizing the products of cDNA amplification with a diagnostic ${ }^{32} \mathrm{P}$-end-labeled 50-base oligomer corresponding to a region within the amplified $c-m y b$ mRNA from nucleotides $2,351-2,400$ (14). 


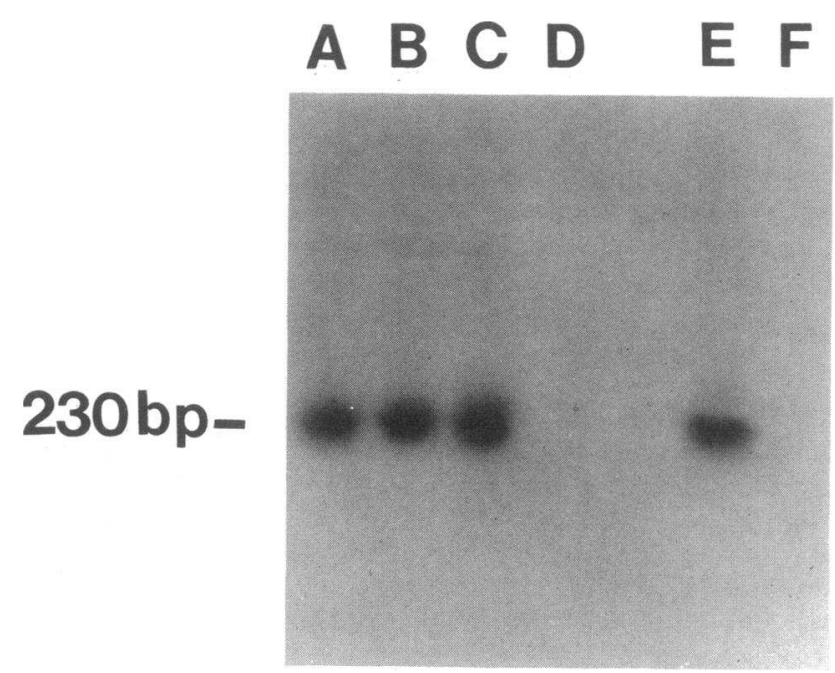

Figure 7. Kinetics of expression of c-myb mRNA in MY $10^{+} \mathrm{MNC}$ cultured in the presence of GM-CSF and IL-3. Detection of c-myb mRNA was as described in Fig. 6. Experiment 1: $\left(A\right.$, MY $10^{+} \mathrm{MNC}$ RNA at day $0 ; B, \mathrm{MY} 10^{+} \mathrm{MNC}$ at day $4 ; C, \mathrm{MY} 10 \mathrm{MNC}$ at day 8; $D, \mathrm{MY} 10^{+} \mathrm{MNC}$ at day 14$)$; experiment 2: $\left(E, \mathrm{MY} 10^{+} \mathrm{MNC}\right.$ at day $0 ; F, \mathrm{MY} 10^{+} \mathrm{MNC}$ at day 14 ).

CFU-GM progenitors (MY10 ${ }^{+} \mathrm{MNC}$ ) is manifested as a reduction in colony size (Table II). Analogous results were obtained from CFU-GM growth from peripheral blood (not shown), which contains only the more immature progenitors $(30,32)$. Exposure of the more mature CFU-G to the c-myb antisense oligomer resulted in a significant decrement in colony size (Table I). CFU-G have very high proliferative activity (50\% of the cells in S phase; 29), but the number of cells per colony is much higher than that of the analogous late progenitors in the erythroid compartment (CFU-E; Table I). This may explain why the antisense myb oligomer reduces CFU-E derived colony formation while the effect on CFU-G is primarily manifested as reduction in colony size.

The differential effect the c-myb antisense oligomers on early and late progenitors could have occurred as consequence of differences in cellular uptake of these oligomers that affects their ability to inhibit c-myb function equally in both progenitor types. The experiment in Fig. 6 suggests that c-myb oligomers are taken up with similar efficiency by the majority of $\mathrm{A}^{-} \mathrm{T}^{-} \mathrm{MNC}$ and $\mathrm{MY} 10^{+} \mathrm{MNC}$ since in both cases c-myb mRNA was no longer detectable in the presence of the antisense oligomer. However, the data do not prove unequivocally that $c-m y b$ antisense oligodeoxynucleotides equally inhibit $c-m y b$ function in the colony-forming progenitors of each compartment, since these cells are a minority both in $\mathrm{A}^{-} \mathrm{T}^{-} \mathrm{MNC}$ and in $\mathrm{MY}^{-10^{+}} \mathrm{MNC}$. On the other hand, exposure

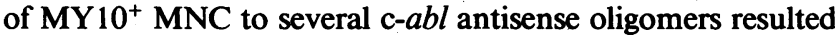
in a significant inhibition of CFU-GM colony formation (22a), validating the assumption that specific gene functions are inhibited in $\mathrm{MY} 10^{+}$progenitors exposed to synthetic oligomers.

We have also noted that exposure of early and late progenitors to c-myc antisense oligodeoxynucleotides does not have measurable effects on in vitro hematopoietic colony growth. It has been shown that the expression of a c-myc antisense construct introduced by transfection in Friend murine erythro- leukemia cells accelerates erythroid differentiation in response to a DMSO (33) and that exposure of HL-60 cells to a c-myc antisense oligomer inhibits proliferation and induces terminal differentiation (10). In contrast, exposure of HL-60 cells to a c- $m y b$ antisense oligomer does not induce differentiation (19). These findings suggest that $c-m y b$ and $c-m y c$ play different roles in regulating hematopoietic growth and differentiation: downregulation of c-myb expression might directly affect hematopoietic proliferation, whereas low levels of c-myc protein might be necessary to allow hematopoietic cells to enter the differentiation pathway $(10,33)$. If downregulation of c-myc expression also accelerates the differentiation of normal marrow progenitors it would be difficult to observe such effect under the standard conditions of colony formation we used.

In summary, our findings suggest that c-myb function is most needed in the compartments containing the highest number of progenitors in S phase, and is less vital to the maintenance of compartments containing earlier progenitors with low proliferative activity. Nevertheless, while these results suggest that c-myb protein is most important for cells that are actively proliferating, we cannot exclude the possibility that actively cycling progenitors undergo maturational changes that may render the cells more dependent on $c-m y b$ function. In this regard, it has been suggested that $c-m y b$ protein levels may correlate better with cell maturation than cell proliferative activity in normal bone marrow progenitor cells (23). Since the total number of colonies of any type derived from $\mathrm{MY} 10^{+}$progenitors is not decreased in comparison with controls it is also clear that inhibition of c-myb function did not adversely affect lineage commitment. Of more general importance, these studies should enable more rigorous analyses of many other genes with potentially important roles in normal hematopoietic development.

\section{Acknowledgments}

We thank Renato Baserga for critical review of the manuscript; J. K. DeRiel for synthesis of the oligonucleotides; S. Clark for the recombinant human GM-CSF and IL-3; and G. Rovera for G-CSF.

This work was supported in part by National Institutes of Health (NIH) grants CA-36896, CA-01324 (to Dr. Gewirtz), and CA-46782 (to Dr. Calabretta), and grant $\mathrm{CH}-455$ from the American Cancer Society (to Dr. Calabretta). Dr. Caracciolo was supported in part by a grant from the Italian Association of Cancer Research. Dr. Gewirtz is the recipient of a Research Career Development Award from the National Cancer Institute, NIH. Dr. Calabretta is a Scholar of the Leukemia Society of America.

\section{References}

1. Till, J. E., and E. A. McCulloch. 1980. Hemopoietic stem cell differentiation. Biochim. Biophys. Acta. 605:431-459.

2. Metcalf, D. 1985. The granulocyte-macrophage colony-stimulating factors. Science (Wash. DC). 229:16-22.

3. Bradley, T. R., and D. Metcalf. 1966. Growth of mouse bone marrow cells in vitro. Aust. J. Exp. Biol. Med. Sci. 44:287-296.

4. Ichikawa, Y., D. H. Pluznik, and L. Sachs. 1966. In vitro control of development of macrophage and granulocyte colonies. Proc. Natl. Acad. Sci. USA. 56:488-492.

5. Pike, B. L., and W. A. Robinson. 1970. Human bone marrow colony growth in agar gel. J. Cell Physiol. 76:77-85.

6. Clark, S. C., and R. Kamen. 1987. The human hematopoietic colony-stimulating factors. Science (Wash. DC). 236:1229-1237. 
7. Seiff, C. A. 1987. Hematopoietic growth factors. J. Clin. Invest. 79:1549-1557.

8. Zamecnik, P. C., J. Goodchild, Y. Taguchi, and P. S. Sarin. 1986. Inhibition of replication and expression of human T-cell lymphotropic virus type III in culture cells by exogenous synthetic oligonucleotides complementary to viral RNA. Proc. Natl. Acad. Sci. USA. 83:4143-4146.

9. Heikkila, R., G. Schwab, E. Wickstron, S. L. Loke, D. H. Pluznik, R. Watt, and L. M. Neckers. 1987. A c-myb antisense oligodeoxynucleotides inhibite entry into $S$ phase but not progress from $G_{0}$ to $\mathrm{G}_{1}$. Nature (Lond.). 328:445-449.

10. Holt, J. T., R. L. Redner, and A. W. Nienhuis. 1988. An oligomer complementary to c-myc messenger-RNA inhibits proliferation of HL-60 promyelocytic cells and induces differentiation. $\mathrm{Mol}$. Cell. Biol. 8:963-973.

11. Gewirtz, A. M., and B. Calabretta. 1988. A c-myb antisense oligodeoxynucleotide inhibits normal human hematopoiesis in vitro. Science (Wash. DC). 242:1303-1306.

12. Caracciolo, D., N. Shirsat, G. G. Wong, B. Lange, S. Clark, and G. Rovera. 1987. Recombinant human M-CSF requires sublimina concentration of GM-CSF for optimal stimulation of human macrophage colony formation in vitro. J. Exp. Med. 166:1851-1860.

13. Civin, C. I., L. C. Strauss, C. Brovall, M. J. Fackler, J. F. Schwartz, and J. H. Shaper. 1984. A hematopoietic progenitor cell surface antigen defined by a monoclonal antibody raised against KG-la cells. J. Immunol. 133:157-165.

14. Majello, B., L. C. Kenyon, and R. Dalla-Favera. 1986. Human c-myb proto-oncogene: nucleotide sequence of cDNA and organization of the genomic locus. Proc. Natl. Acad. Sci. USA. 83:9636-9640.

15. Watt, R., L. W. Stanton, K. B. Marcu, R. C. Gallo, C. M. Croce, and G. Rovera. 1983. Nucleotides sequence of cloned cDNA of the human c-myc oncogene. Nature (Lond.). 303:725-728.

16. Rappolee, D. A., D. Mark, M. J. Benda, and Z. Werb. 1988. Wound macrophages express TGF- and other growth factors in vitro: analysis by mRNA phenotyping. Science (Wash. DC). 241:708-712.

17. Saiki, R. K., D. H. Gelfand, S. Stoffel, S. J. Scharf, R. Higuchi, G. T. Horn, K. B. Mullils, and H. A. Erlich. 1988. Primer-directed enzymatic amplification of DNA with a thermostable DNA polymerase. Science (Wash. DC). 239:487-491.

18. Maniatis, T., E. F. Fritsch, and J. Sambrook. 1982. Molecular Cloning: A Laboratory Manual. Cold Spring Harbor Laboratory, Cold Spring Harbor, NY. 545 pp.

19. Anfossi, G., A. M. Gewirtz, and B. Calabretta. 1989. An oligomer complementary to c-myb encoded mRNA inhibits proliferation of human myeloid leukemia cell lines. Proc. Natl. Acad. Sci. USA. 86:3379-3383

20. Gewirtz, A. M., G. Anfossi, D. Venturelli, S. Valpreda, R. Sims, and B. Calabretta. 1989. $G_{1} / S$ transition in normal human T-lympho- cytes requires the nuclear protein encoded by c-myb. Science (Wash. DC). 245:180-183.

21. Brandt, J., N. Baird, L. Lu, E. Srour, and R. Hoffman. 1988. Characterization of a human hematopoietic progenitor cell capable of forming blast cell containing colonies in vitro. J. Clin. Invest. 82:1017-1027.

22. Dash, P., I. Lotan, M. Knapp, E. R. Kandel, and P. Goelet. 1987. Selective elimination of mRNA in vivo: complementary oligodeoxynucleotides promote RNA degration by an RNase H-like activity. Proc. Natl. Acad. Sci. USA. 84:7896-7900.

22a. Caracciolo, D., M. Valtieri, D. Venturelli, C. Peschle, A. M. Gewirtz, and B. Calabretta. 1989. Lineage specific requirement of c- $a b l$ function in normal hematopoiesis. Science (Wash. DC). 245:1107-1109.

23. Kastan, M. B., D. J. Slamon, and C. I. Civin. 1989. Expression of proto-oncogene c-myb in normal human hematopoietic cells. Blood. 73:1444-1451.

24. Sachs, L. 1987. The molecular control of blood cell development. Science (Wash. DC). 238:1374-1379.

25. Weinberg, R. A. 1985. The action of oncogenes in the cytoplasm and nucleus. Science (Wash. DC). 230:770-776.

26. Westin, E. H., R. E. Gallo, S. K. Arya, A. Eva, L. M. Souza, M. A. Baluda, S. A. Aaronson, and F. Wong-Staal. 1982. Differential expression of the amv-gene in human hematopoietic cells. Proc. Natl. Acad. Sci. USA. 79:2194-2198.

27. Gonda, T. J., and D. Metcalf. 1984. Expression of myb, myc, and fos protooncogenes during the differentiation of a murine myeloid leukemia. Nature (Lond.). 310:249-251.

28. Clarke, M. D., J. F. Kukowska-Latallo, E. Westin, M. Smith, and E. V. Prochownik. 1988. Constitutive expression of a c-myb cDNA blocks Friend murine erythroleukemia cells differentiation. Mol. Cell. Biol. 8:884-882.

29. Lipton, J. M., M. Kudish, and D. G. Nathan. 1981. Response of three clones of human erythroid progenitors to the absence of erythropoietin in vitro as a measure of progenitor maturity. Exp. Hematol. (NY). 9:1035-1041.

30. Ferrero, D., H. E. Broxmeyer, G. L. Pagliardi, S. Venuta, B. Lang, S. Pessano, and G. Rovera. 1983. Antigenically distinct subpopulations of myeloid progenitor cells (CFU-GM) in human peripheral blood and marrow. Proc. Natl. Acad. Sci. USA. 80:4114-4118.

31. Iscove, N. N. 1977. Role of erythropoietin in regulation of population size and cell cycle of early and late erythroid precusors in mouse marrow. Cell Tissue Kinet. 10:323-350.

32. Tebbi, K., L. Rubin, D. H. Cowan, and E. A. McCulloch. 1978. Granulopoiesis in culture from blood and marrow cells of nonleukemic individuals and patients with acute leukemia. Blood. 48:235-243.

33. Prochownick, E. V., J. Kukowska, and C. Rodgers. 1988. c-myc antisense transcripts accelerate differentiation and inhibit $G_{1}$ progression in murine erythroleukemia cells. Mol. Cell. Biol. 8:3683-3695. 